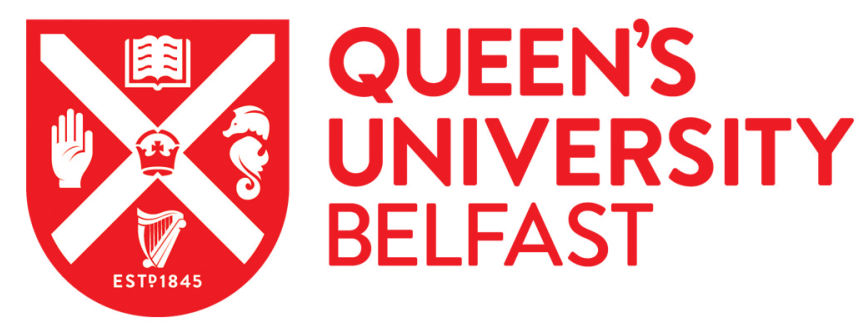

\title{
QUANTITATIVE ANALYSIS OF HYPERAUTOFLUORESCENT RINGS TO CHARACTERIZE THE NATURAL HISTORY AND PROGRESSION IN RPGR-ASSOCIATED RETINOPATHY
}

Tee, J. J. L., Kalitzeos, A., Webster, A. R., Peto, T., \& Michaelides, M. (2017). QUANTITATIVE ANALYSIS OF HYPERAUTOFLUORESCENT RINGS TO CHARACTERIZE THE NATURAL HISTORY AND PROGRESSION IN RPGR-ASSOCIATED RETINOPATHY. Retina (Philadelphia, Pa.), 1-14.

https://doi.org/10.1097/IAE.0000000000001871

\section{Published in:}

Retina (Philadelphia, Pa.)

\section{Document Version:}

Publisher's PDF, also known as Version of record

Queen's University Belfast - Research Portal:

Link to publication record in Queen's University Belfast Research Portal

\section{Publisher rights}

Copyright 2017 the authors.

This is an open access article published under a Creative Commons Attribution-NonCommercial-NoDerivs License

(https://creativecommons.org/licenses/by-nc-nd/4.0/), which permits distribution and reproduction for non-commercial purposes, provided the author and source are cited

\section{General rights}

Copyright for the publications made accessible via the Queen's University Belfast Research Portal is retained by the author(s) and / or other copyright owners and it is a condition of accessing these publications that users recognise and abide by the legal requirements associated with these rights.

\section{Take down policy}

The Research Portal is Queen's institutional repository that provides access to Queen's research output. Every effort has been made to ensure that content in the Research Portal does not infringe any person's rights, or applicable UK laws. If you discover content in the

Research Portal that you believe breaches copyright or violates any law, please contact openaccess@qub.ac.uk. 


\section{QUANTITATIVE ANALYSIS OF \\ HYPERAUTOFLUORESCENT RINGS TO \\ CHARACTERIZE THE NATURAL HISTORY \\ AND PROGRESSION IN RPGR- ASSOCIATED RETINOPATHY}

JAMES J. L. TEE, MBBS, FRCOPhTH, ${ }^{*} \dagger$ ANGELOS KALITZEOS, PhD, ${ }^{*} \dagger$ ANDREW R. WEBSTER, MD, FRCOPHTH, $* \dagger$ TUNDE PETO, MD, PHD, $*+\neq$ MICHEL MICHAELIDES, MD, FRCOPHTH $* \dagger$

Purpose: Quantitative analysis of hyperautofluorescent rings and progression in subjects with retinitis pigmentosa associated with retinitis pigmentosa GTPase regulator $(R P G R)$ gene mutations.

Methods: Prospective observational study of 46 subjects. Ring area, horizontal and vertical diameter measurements taken from outer and inner ring borders. Intraobserver repeatability, baseline measurements, progression rates, interocular symmetry, and association with age and genotype were investigated.

Results: Baseline ring area was $11.8 \pm 13.4 \mathrm{~mm}^{2}$ and $11.4 \pm 13.2 \mathrm{~mm}^{2}$ for right and left eyes, respectively, with very strong interocular correlation $(r=0.9398 ; P<0.0001)$. Ring area constriction was $1.5 \pm 2.0 \mathrm{~mm}^{2} /$ year and $1.3 \pm 1.9 \mathrm{~mm}^{2} /$ year for right and left eyes, respectively, with very strong interocular correlation $(r=0.878, P<0.0001)$. Baseline ring area and constriction rate correlated negatively with age $(r=-0.767 ; P<0.0001$ and $r=-0.644, P<0.0001$, respectively). Constriction rate correlated strongly with baseline area $(r=0.850, P<0.0001)$. Age, but not genotype, exerted a significant effect on constriction rates $(P<0.0001)$, with greatest rates of progression seen in younger subjects. An exponential decline overall was found.

Conclusion: This study provides disease-specific baseline values and progression rates together with a repeatability assessment of fundus autofluorescence metrics. Our findings can guide future treatment trials and contribute to the clinical care of patients with RPGR-associated retinitis pigmentosa.

RETINA 0:1-14, 2017

$\mathrm{R}$ etinitis pigmentosa (RP) as a collection of genetically diverse disorders is a common form of retinal degeneration with a prevalence of 1:3,000; with $30 \%$ to $40 \%$ of cases inherited through an autosomal dominant (AD) route, $45 \%$ to $60 \%$ through an autosomal recessive (AR) route, and $5 \%$ to $15 \%$ as an X-linked trait. ${ }^{1-6}$ Three quarters of X-linked RP (XLRP) can be attributed to mutations arising within the retinitis pigmentosa GTPase regulator (RPGR) gene. ${ }^{6-8} R P G R$-associated retinopathy is especially severe, as characterized by early disease onset in childhood and fast progression. ${ }^{9}$

Fundus autofluorescence (FAF) is an established modality for studying retinal structure (and indirectly function) in vivo in RP. ${ }^{10-24}$ The FAF signal is believed to be derived predominantly from accumulation of lipofuscin/related metabolites in the retinal pig- ment epithelium ${ }^{25}$ secondary to photoreceptor outer segment phagocytosis. ${ }^{26}$ Increased lipofuscin levels have been correlated with photoreceptor loss. ${ }^{27}$ The presence of abnormally high FAF signal intensity in surviving areas of retina where metabolic activity is high and low or absent signals in regions of outer retinal atrophy has been demonstrated in RP. ${ }^{10,28}$ Specifically, a parafoveal ring of hyperautofluorescence that constricts over time is evident in patients with RP. ${ }^{13,15-20,24}$ Ring size has been correlated with retinal function as determined by static and kinetic perimetry, microperimetry, and electrophysiological testing (pattern ERG P50 and multifocal ERG amplitudes), with greater preservation of visual function seen in eyes with larger rings. ${ }^{11-15,22,23}$ Retinal sensitivity has been found to be relatively well preserved within the ring and conversely 
low or absent in retinal locations outside the ring. ${ }^{12,19,21,22}$ Thus, FAF imaging in RP has been demonstrated to be related to visual function and can thereby indirectly provide information regarding macular function. Importantly, this high-signal ring has structural correlates with the inner border of the ring delineating the limits of a relatively intact ellipsoid zone on spectral domain optical coherence tomography. ${ }^{15-17,19-22}$

The lack of $R P G R$-associated retinopathy-specific natural history data hampers current efforts to predict factors that may guide both recruitment of suitable candidates for upcoming gene therapy trials and defining which modalities are most suitable for assessing structural measures of success in these trials. Most aforementioned data were derived from RP patients without an established genotype and thereby inherently limit the generalizability of such results. We herein investigate the suitability of FAFderived metrics in determining baseline characteristics and disease progression in a cohort of molecularly proven $R P G R$ subjects. We have explored and quantified the following: 1) incidence of FAF rings; 2) baseline measurements of FAF rings; 3) suitability and reliability of a broad range of FAF-derived ring metrics in ring quantification; 4) change in ring metrics over time; 5) interocular symmetry of baseline measurements and progression rates; 6) association between baseline ring size and age; 7) associations between progression rates and a) age, b) baseline ring metrics, and c) genotype.

\section{Patients, Methods, and Statistical Analysis}

Ethical approval was granted by the ethics committee at Moorfields Eye Hospital for this prospective

From the *UCL Institute of Ophthalmology, University College London, London, United Kingdom; †Moorfields Eye Hospital, London, United Kingdom; and \$Queen’s University Belfast, Belfast, United Kingdom.

Supported by grants from the National Institute for Health Research Biomedical Research Centre at Moorfields Eye Hospital National Health Service Foundation Trust and UCL Institute of Ophthalmology (United Kingdom), Fight For Sight (United Kingdom), Moorfields Eye Hospital Special Trustees (United Kingdom), Moorfields Eye Charity (United Kingdom), the Foundation Fighting Blindness (USA), Retinitis Pigmentosa Fighting Blindness (United Kingdom), and the Wellcome Trust $(099173 / \mathrm{Z} / 12 / \mathrm{Z})$. M. Michaelides is supported by an FFB Career Development Award.

M. Michaelides consults for MeiraGTx and Astellas. The remaining authors have no conflicts of interest to disclose.

This is an open-access article distributed under the terms of the Creative Commons Attribution-Non Commercial-No Derivatives License 4.0 (CCBY-NC-ND), where it is permissible to download and share the work provided it is properly cited. The work cannot be changed in any way or used commercially without permission from the journal.

Reprint requests: Michel Michaelides, MD, FRCOphth, UCL Institute of Ophthalmology, 11-43 Bath Street, London EC1V 9EL, United Kingdom; e-mail: michel.michaelides@ucl.ac.uk observational study that is supplemented with FAF images collected prospectively during routine clinical care. Adherence to the Declaration of Helsinki was observed throughout the study. In addition to 33 subjects with bilateral rings who are participants in our on-going $R P G R$ prospective natural history study, an additional 13 subjects were identified through searching the Moorfields Inherited Eye Disease Database. All subjects were affected males with RP associated with likely disease-causing variants in $R P G R$. Detailed inclusion and exclusion criteria are provided in Figure 1.

All images were acquired by dedicated ophthalmic photographers with either the Spectralis Heidelberg Retina Angiograph (HRA) +OCT device (Heidelberg Engineering, Heidelberg, Germany) or Spectralis HRA2 device (Heidelberg Engineering). A 488-nm excitational wavelength laser and a barrier filter of $500 \mathrm{~nm}$ were used for imaging. Images were acquired in either $30^{\circ}, 35^{\circ}$, or $55^{\circ}$ field of view as deemed appropriate at time of imaging. Image analysis with vendor software (Heidelberg Eye Explorer Region Finder version 2.4.3.0) was subsequently performed for each FAF image with the following methods:

1) The outer ring border was first delineated in an ellipsoid shape and ring area obtained from the software, as shown in Figure 2. 2) The Early Treatment Diabetic Retinopathy Study grid was next placed onto the foveal center of the image, as defined by the darkest central spot within the hypofluorescent foveal center. The grid was then adjusted clockwise or anticlockwise to compensate for image rotation, so that its horizontal meridian corresponded to the true horizontal meridian of the fundus image (as determined by the extrapolation of a straight line running from the middle of the optic disk to the foveal center). After adjustment for image rotation, the outer border horizontal diameter was measured-taken from bisecting points of the temporal outer ring border and horizontal grid meridian from one end, passing through the foveal center, and terminating at the bisecting points nasally (Figure 2). The outer border vertical diameter measurement was then taken, from superior to inferior bisecting points (Figure 2). 3) This method was subsequently repeated for inner border-derived measurements, by delineating the inner ring border to obtain inner ring area. 4) Horizontal and vertical diameter measurements running from the inner border through the foveal center were then made based on the same technique as described above for outer border metrics.

The most recent image for each eye of all subjects was measured twice by a single observer, a minimum of 1 week apart and in random order of the images, to assess the level of intraobserver repeatability. Measurements were kept apart by laterality and only one 


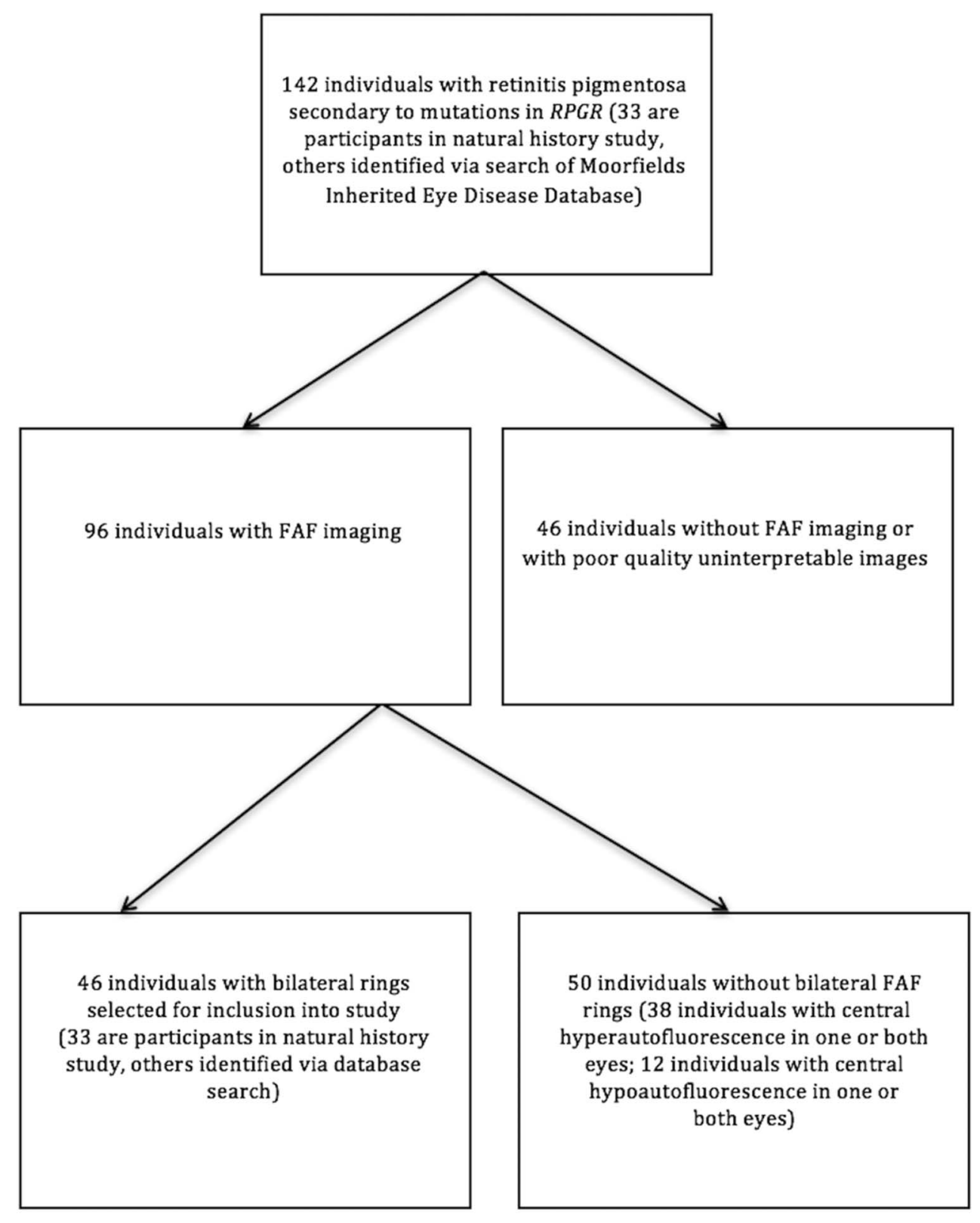

Fig. 1. Flowchart illustrating recruitment of subjects based on the inclusion and exclusion criteria.

image per eye per subject was used to maintain the "independence-of-scores" and to avoid inducing systematic bias. Calculation of mean \pm SD of within-pair differences and 95\% limits of agreement (LOA) were performed with the Bland-Altman method. Repeatability coefficients and test-retest variability for all ring metrics were calculated and these are provided in Table 1, together with corresponding mean overall annual constriction rates for each metric that were calculated from rates of individual subjects as described: all ring metrics measurements (outer and inner border-derived ring area, horizontal and vertical diameters) were plotted on scatter plots as a function of age for each subject, with right eyes kept separate from left eyes. Rates of constriction for each metric for each eye of each subject were obtained from gradients of individual trendlines fitted to data points using a least squares method (Microsoft Excel for Mac version 15.24). Figure 3 provides an example of trendlines for individual subjects fitted to data from outer border-derived ring area measurements of right eyes.

Statistical analysis was performed with XLSTAT version 18.07 software (Addinsoft, New York, NY). Data are expressed as mean values, with SD and 95\% confidence intervals provided were stated. Data were inspected for normality with $\log _{10}$ transformation performed before conducting tests of statistical analyses. 


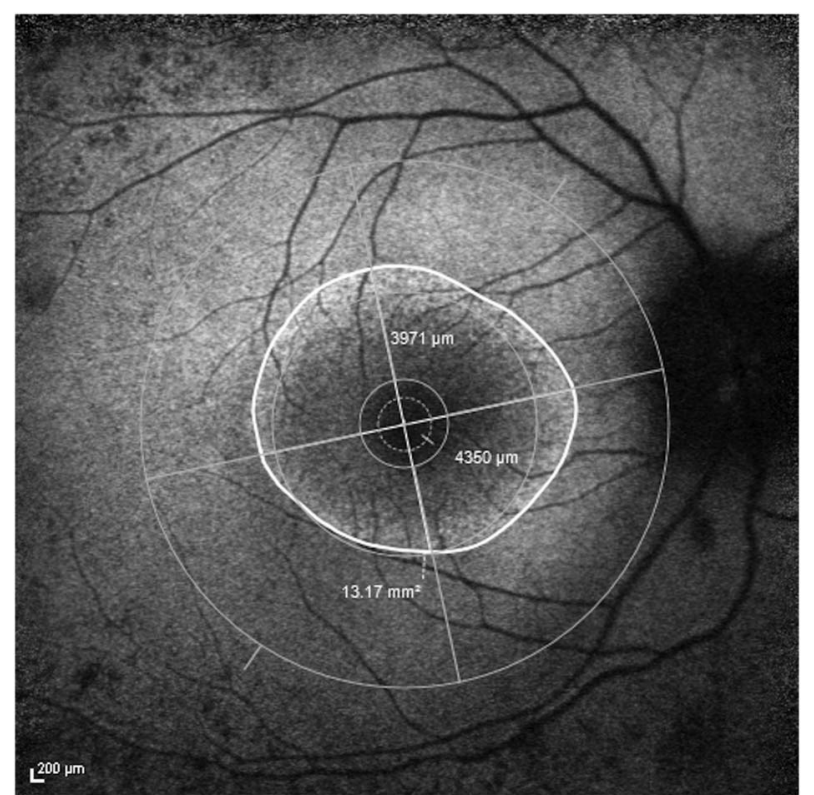

Fig. 2. FAF image of the right eye of a subject with superimposed Early Treatment Diabetic Retinopathy Study grid centered on the fovea with anticlockwise adjustment of the vertical and horizontal meridians. Ring area was $13.17 \mathrm{~mm}^{2}$, horizontal diameter was $4,350 \mu \mathrm{m}$, and vertical diameter was $3,971 \mu \mathrm{m}$. All measurements in this example were obtained from the outer border.

Interocular differences in baseline ring size quantified with outer border metrics were assessed for significance with the two-tailed paired-samples $t$-test. Pearson's correlation coefficient was calculated to investigate interocular associations of symmetry. Interocular differences in constriction rates derived from outer border metrics were also investigated with the two-tailed paired-samples $t$-test and Pearson's correlation coefficient.

After this, data from right and left eyes were combined for further analyses. Associations between constriction rates about with respect to baseline measurements and age were investigated with Pearson's correlation coefficient.

A two-way analysis of variance (ANOVA) was performed to investigate the effects of age, genotype, and the interaction of both factors on constriction rates. Genotype was divided into 2 categories depending on $R P G R$ sequence variant position: Exon 1 to 14 or Open Reading Frame 15 (ORF15) variants. Age was divided into 5 categories: Category $1=<10$ years of age, Category $2=10$ to $<15$ years, Category $3=15$ to $<20$ years, Category $4=20$ to $<25$ years, and Category $5=25$ years of age and above. Post hoc multiple pairwise comparisons were performed with Tukey's test in instances of a significant ANOVA result. Significance level alpha for statistical tests was set at 0.0167 after Bonferroni correction, as tests were simultaneously conducted on 3 ring metrics.

\section{Results}

\section{Cohort Characteristics}

Ninety-six subjects with FAF imaging were identified in total, of which 46 possessed bilateral rings, as shown in Figure 1. In addition, 38 subjects had a central hyperautofluorescence pattern in the absence of rings in one or both eyes, and 12 subjects had a central hypoautofluorescence pattern in the absence of rings in one or both eyes. The age of subjects (mean $\pm \mathrm{SD}$, given in years) in the 3 aforementioned FAF groups are $16.3 \pm 7.9$ for the bilateral rings group, $35.1 \pm 8.8$ for the central hyperautofluorescence group, and 53.7 \pm 12.2 for the central hypoautofluorescence group. Subject age was calculated from birth to time of baseline FAF image acquisition. The proportion of subjects with bilateral rings distributed in respective age categories are as follows: $19.6 \%$ in age Category $1 ; 17.4 \%$ in age Category $2 ; 30.4 \%$ in age Category $3 ; 13.0 \%$ in age Category 4; and $19.6 \%$ in age Category 5 . A total of 19 of the 46 subjects with bilateral rings harbored mutations in RPGR exons 1 to 14 and 27 in ORF15.

Forty of the 46 subjects had follow-up imaging performed. Mean follow-up period was $49.1 \pm 31.2$ months (range from 9.1 to 141.6 months). Subjects were followed at variable time intervals. Thirty-four subjects had $\geq 20$ months of FAF follow-up, 5 subjects with 12 months' follow-up, and 1 with follow-up of 9 months. Most subjects (33/40) underwent three or more FAF observations during their follow-up period. Of the 40 subjects with follow-up, a median of 4 FAF observations per subject (range from 2 to 8 observations) giving rise to a total of $168 \mathrm{FAF}$ observations overall were completed.

\section{Metric Repeatability}

The results of intraobserver variability assessment and mean annual rates of constriction for each metric are provided in Table 1 . It can be seen that variability is least for outer border metrics. Hence, baseline measurements and constriction rates described henceforth are those derived from the outer border.

\section{Baseline Outer Border Ring Metrics and Constriction Rates}

Baseline outer border ring measurements for both eyes of all 46 subjects with corresponding $P$ values from interocular comparisons are provided in Table 2. Differences in mean of right and left eyes for all outer border metrics were not statistically significant, and all three metrics were very strongly correlated at baseline with $\mathrm{r} \geq 0.9310$ and $P<0.0001$. 
Table 1. Repeatability Indices Derived From Repeated Measurements of Most Recent FAF Images for Each Subject

\begin{tabular}{|c|c|c|c|c|c|c|c|c|c|}
\hline \multirow{2}{*}{$\begin{array}{l}\text { Outer Border } \\
\text { Metrics }\end{array}$} & \multicolumn{3}{|c|}{ Ring Area } & \multicolumn{3}{|c|}{ Horizontal Diameter } & \multicolumn{3}{|c|}{ Vertical Diameter } \\
\hline & Right Eyes & Left Eyes & Both Eyes & Right Eyes & Left Eyes & Both Eyes & Right Eyes & Left Eyes & Both Eyes \\
\hline $\begin{array}{l}\text { Mean } \pm \text { SD } \\
\text { of intraobserver } \\
\text { within-pair difference* }\end{array}$ & $0.10 \pm 0.46$ & $0.11 \pm 0.56$ & $0.11 \pm 0.51$ & $65 \pm 151$ & $34 \pm 153$ & $49 \pm 152$ & $37 \pm 133$ & $58 \pm 151$ & $48 \pm 142$ \\
\hline $95 \% \operatorname{LOA}^{*}$ & -0.80 to 1.00 & -0.99 to 1.21 & -0.89 to 1.11 & -231 to 361 & -266 to 334 & -249 to 347 & -224 to 298 & -238 to 354 & -230 to 326 \\
\hline Repeatability coefficient & 0.90 & 1.10 & 1.00 & 296 & 300 & 298 & 261 & 296 & 278 \\
\hline Test-retest variability (\%) & 10.78 & 13.51 & 12.12 & 9.09 & 9.35 & 9.22 & 10.33 & 11.77 & 11.03 \\
\hline $\begin{array}{l}\text { Mean overall annual rate of } \\
\text { constriction }(\%)\end{array}$ & 11.25 & 10.04 & 10.65 & 5.87 & 5.05 & 5.46 & 6.74 & 5.85 & 6.29 \\
\hline \multirow{2}{*}{$\begin{array}{l}\text { Inner Border } \\
\text { Metrics }\end{array}$} & \multicolumn{3}{|c|}{ Ring Area } & \multicolumn{3}{|c|}{ Horizontal Diameter } & \multicolumn{3}{|c|}{ Vertical Diameter } \\
\hline & Right Eyes & Left Eyes & Both Eyes & Right Eyes & Left Eyes & Both Eyes & Right Eyes & Left Eyes & Both Eyes \\
\hline $\begin{array}{l}\text { Mean } \pm \text { SD } \\
\text { of intraobserver } \\
\text { within-pair difference* }\end{array}$ & $0.00 \pm 0.45$ & $-0.16 \pm 0.84$ & $-0.08 \pm 0.68$ & $-12 \pm 197$ & $-52 \pm 200$ & $-32 \pm 199$ & $14 \pm 123$ & $-31 \pm 139$ & $-9 \pm 133$ \\
\hline $95 \% L^{*}{ }^{*}$ & -0.88 to 0.88 & -1.81 to 1.49 & $9-1.41$ to 1.25 & $5-398$ to 374 & -444 to 340 & -422 to 358 & -227 to 255 & -303 to 241 & -270 to 252 \\
\hline $\begin{array}{l}\text { Repeatability coefficient } \\
\text { Test-retest variability (\%) }\end{array}$ & $\begin{array}{c}0.88 \\
2051\end{array}$ & $\begin{array}{c}1.65 \\
3986\end{array}$ & $\begin{array}{c}1.33 \\
3152\end{array}$ & $\begin{array}{c}386 \\
1786\end{array}$ & $\begin{array}{c}392 \\
1886\end{array}$ & 390 & $\begin{array}{c}241 \\
1429\end{array}$ & $\begin{array}{c}272 \\
1627\end{array}$ & $\begin{array}{c}261 \\
1554\end{array}$ \\
\hline $\begin{array}{l}\text { Test-retest variability (\%) } \\
\text { Mean overall annual rate of }\end{array}$ & $\begin{array}{l}20.51 \\
12.97\end{array}$ & $\begin{array}{l}39.86 \\
13.23\end{array}$ & $\begin{array}{l}31.52 \\
13.10\end{array}$ & $\begin{array}{l}17.86 \\
7.67\end{array}$ & $\begin{array}{c}18.86 \\
7.75\end{array}$ & $\begin{array}{c}18.40 \\
771\end{array}$ & 14.29 & 16.27 & 15.54 \\
\hline $\begin{array}{l}\text { Mean overall annual rate of } \\
\text { constriction (\%) }\end{array}$ & 12.97 & 13.23 & 13.10 & 7.67 & 7.75 & 7.71 & 7.20 & 8.06 & 7.64 \\
\hline
\end{tabular}

Mean overall annual rate of constriction for each metric is provided for comparison.

*Units of measurements are millimeter square for ring area and micrometer for horizontal and vertical diameters. 
Fig. 3. Linear trendlines illustrating the progression rates of individual subjects. In this example, the metric used was ring area measurements, derived from the outer borders of subjects' right eyes.

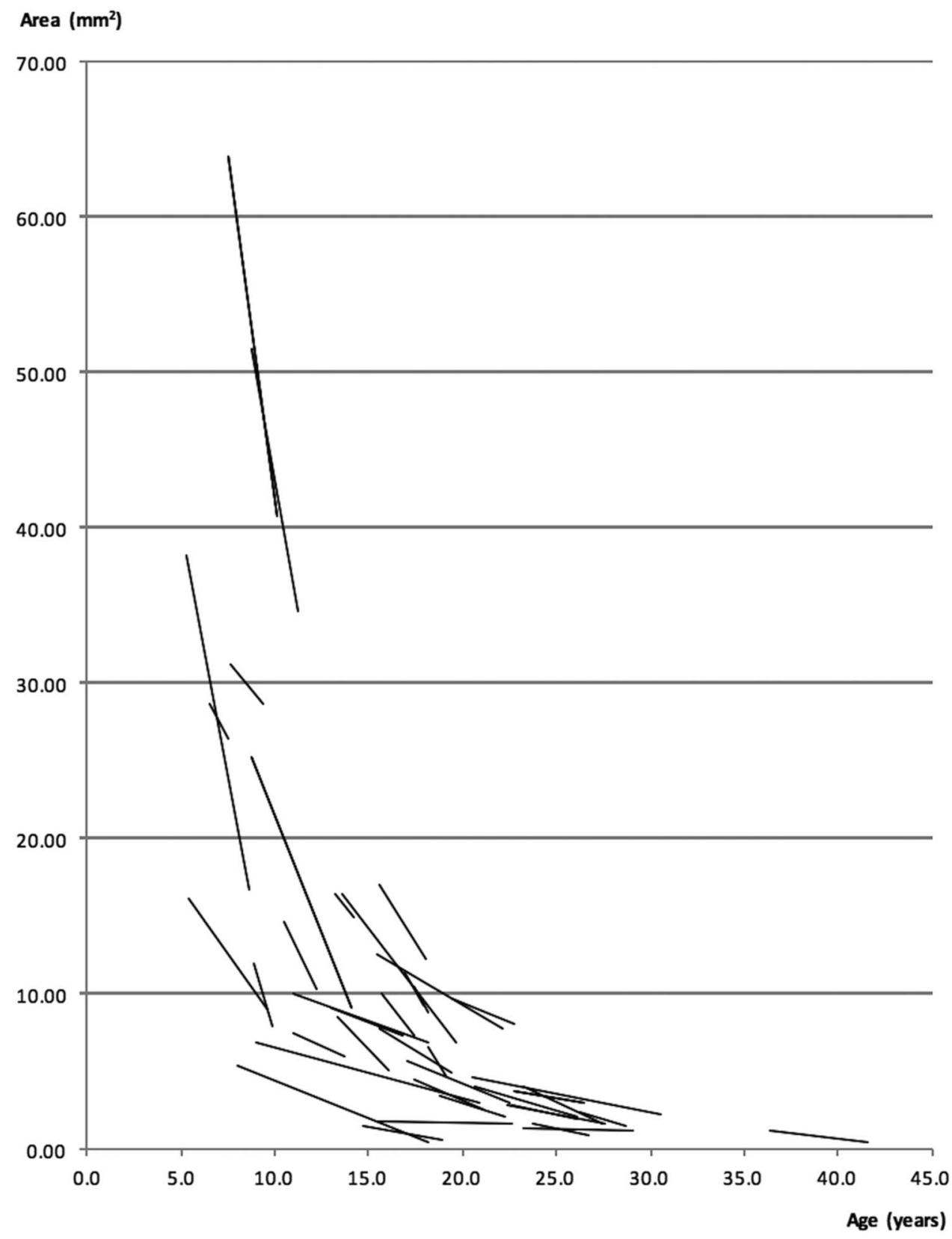

Constriction rates of all ring metrics for each eye of individual subjects were obtained from gradients of linear trendlines as described in the Methods section. In general, linear equations provided the best fit. Figure 3 provides an example of trendlines fitted for each subject. By contrast, Figure 4 shows ring area measurements of all subjects collectively plotted against age. When viewed jointly, the change in area approximates an exponential decline, as confirmed by an exponential equation being the best fit in this instance with an $\mathrm{R}^{2}$ of 0.6867 and 0.6235 for right eyes and left eyes, respectively. The equation for right eyes is given by $\mathrm{y}=50.339$ $\mathrm{e}^{-0.116 \mathrm{t}}$ and for left eyes, $\mathrm{y}=43.742 \mathrm{e}^{-0.110 \mathrm{t}}$, where $\mathrm{y}$ represents ring area in millimeter square and $t$ represents age in years. The rate constant, $\mathrm{k}$, for right eyes is 0.116 and 0.110 for left eyes. Half-lives calculated for right eyes and left eyes are 5.98 and 6.30 years, respectively.

Mean constriction rates, together with results from investigations of interocular differences are provided in Table 3. Differences in constriction rates were insignificant for all three ring metrics. Correlation between constriction rates for right and left eyes was strong and significant for rates derived from vertical diameter measurements $(\mathrm{r}=0.6176, P<0.0001)$ and stronger for rates derived from ring area measurements $(\mathrm{r}=$ $0.8779, P<0.0001)$. Figure 5 illustrates mean 
constriction rates of right and left eyes of subjects in the various age categories. Constriction rates across all three ring metrics were greatest for the youngest age category.

\section{Baseline and Constriction Rate Associations}

After these aforementioned evaluations, data from right and left eyes were combined for further analyses. The association between constriction rates with baseline measurements and age is shown in Table 4. Ring size at baseline as quantified with all three outer border metrics correlated negatively and strongly with age ( $\mathrm{r} \geq-0.7674, P<0.0001$ for all 3). Correlation between constriction rates and baseline size for each of the three metrics was found to be strongest for the area-derived $(\mathrm{r}=0.8502, P<0.0001)$ and vertical diameter-derived metrics $(\mathrm{r}=0.5969, P<0.0001)$. Correlation for the horizontal diameter-derived metric was also significant, albeit weaker $(\mathrm{r}=0.3554, P=$ 0.0012). In addition, area-derived constriction rates showed the strongest negative correlation with age $(\mathrm{r}=-0.6436, P<0.0001)$, whereas that of vertical diameter rates were moderate in strength $(\mathrm{r}=$ $-0.4145, P=0.0001)$.

A two-way ANOVA was performed to investigate the effects of age, genotype, and interaction between age and genotype on constriction rates. Analysis of variance results together with mean $\pm S D$ values for constriction rates in each category are given in Table 5. The effect of age was significant for constriction rates derived from ring area $(P<0.0001)$ and vertical diameter $(P=0.0002)$. Post hoc pairwise comparisons between age categories for area-derived constriction rates disclosed significant differences between younger and older subjects, that is, age Category 1 (youngest) versus all other age categories $(P<0.0001)$; Category 2 versus Category $5(P=0.0072)$; and Category 3 versus Category $5(P=0.0030)$. Similar findings were made with post hoc pairwise comparisons for vertical diameter-derived constriction rates, in that differences between Category 1 versus Category 5 $(P=0.0002)$ and Category 1 versus Category $4(P=$ $0.0064)$ reached statistical significance. The effect of genotype on constriction rates, by contrast, was insignificant.

\section{Discussion}

In this article, we present the first comprehensive FAF study to describe bilateral progression of disease in a cohort comprising entirely of molecularly proven subjects with $R P G R$-associated RP. Forty-eight percent of subjects in our study had 
Fig. 4. Scatter plot of ring area measurements derived from the outer border for right and left eyes of all subjects, plotted collectively against age. An exponential decline is evident.

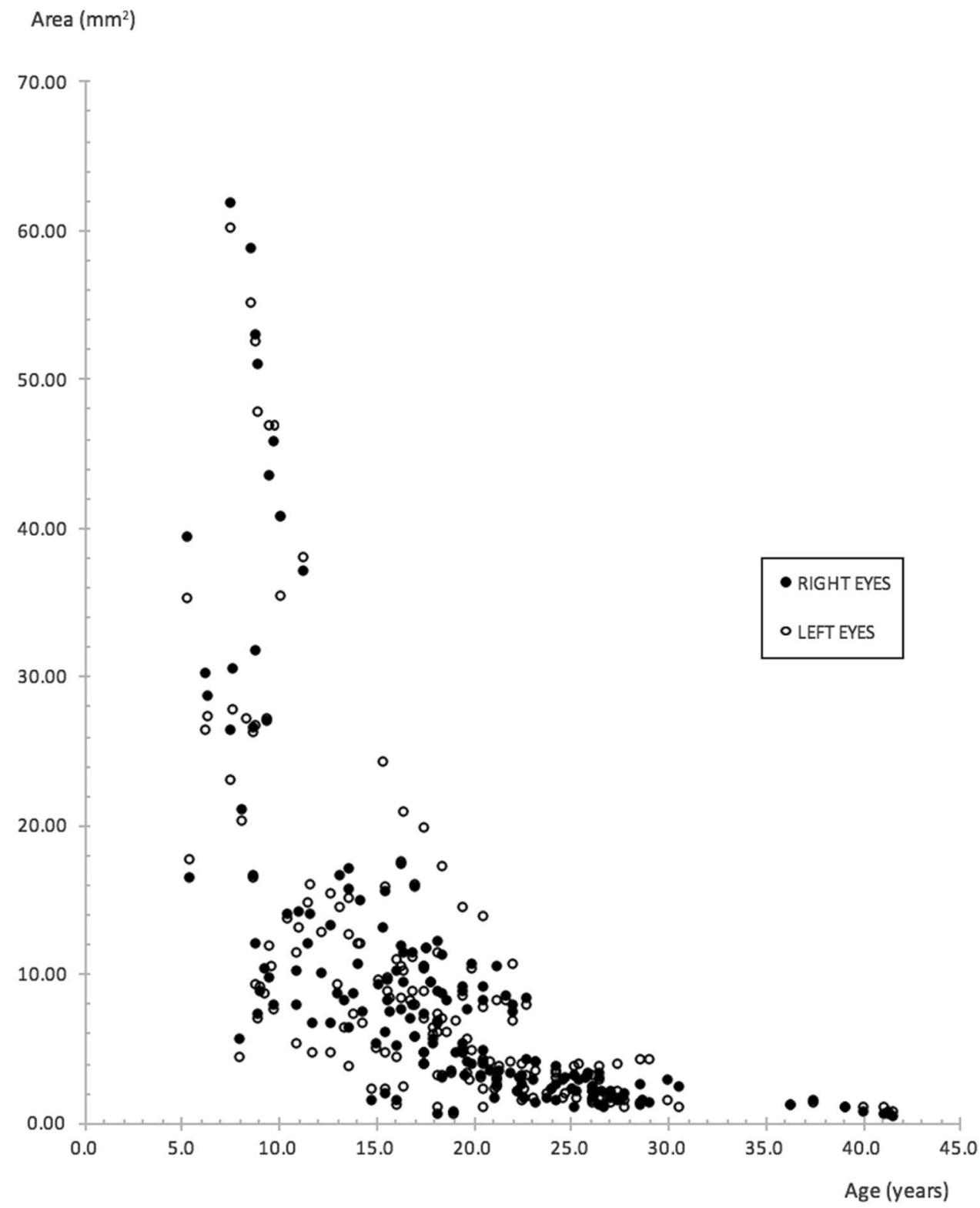

rings, in comparison with $55 \%$ to $69 \%$ described in other RP cohorts. ${ }^{15,19,23,24,29}$ Our subjects with rings are younger in age $(16.3 \pm 7.9$ years of age at time of baseline imaging) in comparison with mean ages of 35 to 49 years described in previous studies. ${ }^{12,18,22,23,29}$ However, these studies were composed of subjects with both ADRP and ARRP and thereby are genetically diverse, with the possible exception of a study investigating Usher syndrome Type I and II-although these are also genetically heterogeneous. ${ }^{19}$ Only one study included subjects with molecularly confirmed XLRP-even then comprising only $6 \%$ of the entire cohort. ${ }^{24}$ It is therefore unsurprising that ring findings (including lack/loss of an FAF ring in older subjects) and other FAF observations that signify more advanced disease at a younger age have been identified in our cohort of molecularly proven $R P G R$ RP subjects, as it is relatively more severe with faster progression compared with other genotypes.

\section{Correlation Between Age and \\ Baseline Measurements}

We found strong and significant negative correlations between age and baseline measurements for all three outer border ring metrics $(\mathrm{r} \geq-0.7674, P<$ 0.0001 for all 3 metrics). Our findings substantiate weaker associations previously reported between age and ring size in cohorts of mixed inheritance. ${ }^{12,17,30} \mathrm{In}$ 
Table 3. Constriction Rates of Each Outer Border Ring Metric for Right and Left Eyes of Subjects

\begin{tabular}{|c|c|c|c|c|c|c|}
\hline \multirow[b]{2}{*}{ Rate Metric } & \multicolumn{2}{|c|}{ Right Eyes $(n=40)$} & \multicolumn{2}{|c|}{ Left Eyes $(n=40)$} & \multirow{2}{*}{$\begin{array}{l}P \text { for Paired- } \\
\text { Samples } t- \\
\text { Test }\end{array}$} & \multirow{2}{*}{$\begin{array}{l}\text { Pearson's } \\
\text { Correlation } \\
\text { Coefficient, r, } \\
\text { With } P\end{array}$} \\
\hline & Mean \pm SD & $95 \% \mathrm{Cl}$ of Mean & Mean \pm SD & $\begin{array}{c}95 \% \mathrm{Cl} \text { of } \\
\text { Mean }\end{array}$ & & \\
\hline $\begin{array}{l}\text { Ring area } \\
\text { constriction, } \\
\mathrm{mm}^{2} / \text { year }\end{array}$ & $1.50 \pm 1.99$ & $0.86-2.14$ & $1.33 \pm 1.90$ & $0.72-1.93$ & 0.0703 & $\begin{array}{l}r=0.8779 \\
\quad P<0.0001\end{array}$ \\
\hline $\begin{array}{l}\text { Horizontal } \\
\text { diameter } \\
\text { constriction, } \\
\mu \mathrm{m} / \text { year }\end{array}$ & $234.94 \pm 186.89$ & $175.17-294.71$ & $193.19 \pm 158.71$ & $142.43-243.95$ & 0.0432 & $\begin{array}{l}r=0.4068 \\
P=0.0092\end{array}$ \\
\hline $\begin{array}{l}\text { Vertical diameter } \\
\text { constriction, } \\
\mu \mathrm{m} / \text { year }\end{array}$ & $225.05 \pm 215.02$ & 156.28-293.81 & $190.73 \pm 198.88$ & $127.12-254.33$ & 0.0885 & $\begin{array}{l}r=0.6176 \\
P<0.0001\end{array}$ \\
\hline
\end{tabular}

Interocular rate differences were assessed for significance with the two-tailed paired-samples $t$-test. Pearson's correlation coefficient, $r$, was calculated to establish associations of interocular symmetry. Statistical analyses with $t$-test and Pearson's correlation were conducted after $\log _{10}$ transformation of variables. Significance level alpha was set at 0.0167 .

$\mathrm{Cl}$, confidence interval.

addition, numerical age can arguably serve as a good approximation for disease duration in RPGR RP given the early onset of disease in childhood typical for the condition. $^{9}$

\section{Progression Rates}

The progression rates described in our study reflect our cohort of molecularly proven $R P G R$ subjects, which overall renders a greater disease severity. This is in contrast with previous studies where cohorts compose of subjects with mixed inheritance and RP of lesser severities. Thus, our mean annual area of autofluorescence constriction rate of $1.42 \mathrm{~mm}^{2}(10.7 \%)$, mean annual horizontal and vertical diameter constriction rates of $214.1 \mu \mathrm{m}(5.5 \%)$ and $207.9 \mu \mathrm{m}(6.3 \%)$, respectively, are greater than previously reported. ${ }^{17-19,24}$ One recent study of 71 subjects where two-thirds had ARRP, 27\% with ADRP, and only 6\% with XLRP found mean annual constriction rates of $147 \mu \mathrm{m}$ (4.1\%) and $121 \mu \mathrm{m}(4.0 \%)$ for horizontal and vertical diameter outer border ring metrics, respectively. ${ }^{24} \mathrm{~A}$ study comprising 8 eyes with ADRP and 6 with ARRP (with no XLRP subjects) reported lower annual outer ring rates of constriction of $2.5 \%$ and $2.1 \%$ for horizontal and vertical diameters, respectively. ${ }^{18} \mathrm{~A}$ mean annual ring constriction rate of $60 \mu \mathrm{m}(3.0 \%)$ calculated from outer border ring radius measurements $(4.0 \%$ with inner border ring radius) was found in 13 patients with Usher syndrome. ${ }^{19}$ Robson et al described $30 \mathrm{RP}$ subjects with a mixed mode of inheritance who underwent serial FAF imaging with a mean follow-up of 4 years from baseline. Progression was seen in 17 subjects, 16 of these had ARRP including Usher syndrome, with a mean annual inner border ring radius constriction rate of $5.6 \% .{ }^{17}$

\section{Overall Exponential Rate of Decline}

To the best of our knowledge, this is the first study to demonstrate an exponential rate of decline in RP on the basis of serial FAF imaging, with the implication that the rate of progression decreases with time (Figure 4). Halflives of outer border-derived ring area calculated separately for right and left eyes are similar at 6 years. Phenotypic heterogeneity in XLRP-RPGR, however, necessitates individual observations. ${ }^{9}$ An exponential decline has previously been demonstrated in functional studies, ${ }^{31-33}$ which were genetically heterogenous with the exception of Iannaccone et $\mathrm{al}^{32}$ who studied subjects with Usher syndrome Type II (which nevertheless was also genetically heterogenous, as subjects were not genetically confirmed). Massof et al observed that the visual field loss occurred exponentially with a similar level of decline across all forms of RP, and this was believed to occur secondary to a common and final process of retinal degeneration. They extrapolated data to estimate the age at which visual field loss began and hypothesized that any difference was due to the earlier onset in XLRP. ${ }^{31}$

We did not set out to directly compare progression between XLRP-RPGR and other forms of RP in our study; however, we note that others have found a greater rate of progression in XLRP. For instance, Birch et $\mathrm{al}^{34}$ found that the inheritance pattern in RP had a significant effect on progression rates, with annual rod electroretinogram threshold elevation being highest in XLRP and lowest in ADRP. Sandberg et $\mathrm{a}^{35}$ observed a greater annual decline in visual field area in subjects with $R P G R$-associated RP, compared with subjects with $R H O$-associated autosomal dominant RP. A $4.7 \%$ mean annual exponential rate of decline was observed for $R P G R$-associated RP, 
Fig. 5. Mean constriction rates for ring area, horizontal, and vertical diameter metrics, for right and left eyes, of subjects grouped within respective age categories. All measurements were obtained from outer borders (age categories: $1=<10$ years of age, $2=10$ to $<15$ years of age, $3=15$ to $<20$ years of age, $4=$ 20 to $<25$ years of age, and $5=$ 25 years of age and above).

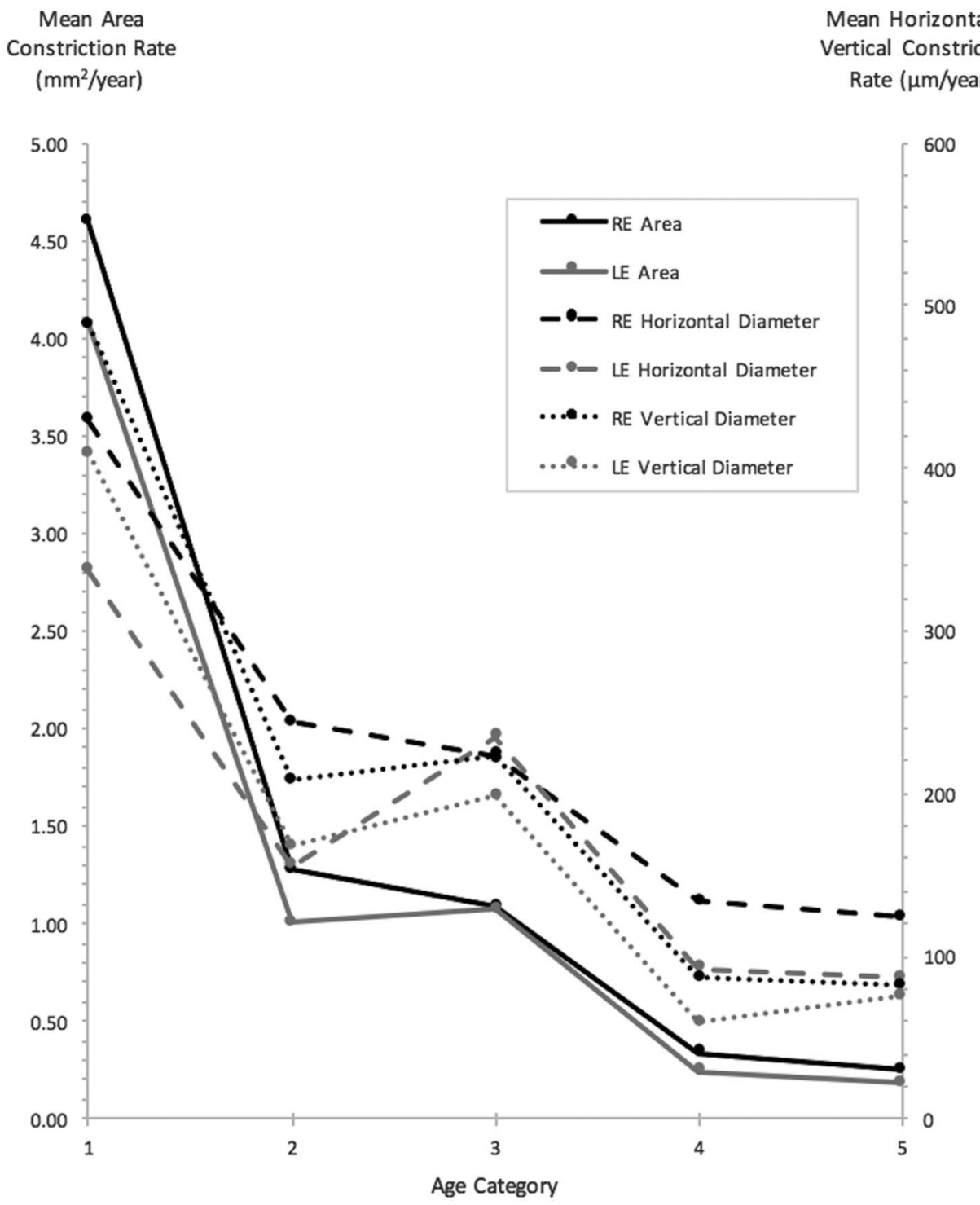

compared with $2.9 \%$ for $R H O$-associated RP. Using structural optical coherence tomography measurements of ellipzoid zone width, Cai et $\mathrm{a}^{36}$ found a significantly greater rate of progression in subjects with XLRP (9.6\%/year) compared with ADRP (3.4\%/year).

\section{Correlation Between Age and Progression}

We found a strong and significant negative correlation between age and rate of area constriction $(\mathrm{r}=-0.6436$, $P<0.0001)$. Correlation between age and rate of vertical diameter constriction was moderate $(\mathrm{r}=-0.4145, P$ $=0.0001$ ), whereas correlation between age and horizontal diameter constriction was weak and insignificant after Bonferroni correction ( $\mathrm{r}=-0.2366, P=0.0346)$. By contrast, Robson et $\mathrm{al}^{17}$ did not find correlation between age and constriction rates, nor did they find correlation between constriction rates and baseline ring size. Sujirakul et $\mathrm{al}^{24}$ also did not find differences in constriction rates with age. Both studies comprised a heterogenous mix of RP subjects with various forms of inheritance patterns. This was alluded to as a reason for noncorrelation by Robson et al. ${ }^{17}$ It is thus possible that potential correlation with age may have been affected by the averaging of results secondary to the inclusion of subjects with different forms of RP, given the wide age range of disease onset and progression rates between different forms. $^{2}$

\section{Correlation Between Baseline Ring Metrics and Progression}

Correlation between baseline size with respective constriction rates was all significant and positive. Area 
Table 4. Associations Between Age With Baseline Measurements, Progression Rates, and Baseline Size With Progression Rates

\begin{tabular}{lrr}
\hline \multicolumn{1}{c}{ Parameters } & Pearson's Correlation Coefficient, $r$ \\
\hline Age with baseline ring & & $P$ \\
Area & -0.7674 & $<0.0001$ \\
Horizontal diameter & -0.7709 & $<0.0001$ \\
$\quad$ Vertical diameter & -0.7692 & $<0.0001$ \\
Age with progression rate quantified & \\
by & & \\
Area constriction & -0.6436 & $<0.0001$ \\
Horizontal diameter constriction & -0.2366 & 0.0346 \\
Vertical diameter constriction & -0.4145 & 0.0001 \\
Size at baseline with constriction & & $<0.0001$ \\
rate of & & 0.0012 \\
Area & & $<0.0001$ \\
Horizontal diameter & 0.8502 & 0.3554 \\
Vertical diameter & 0.5969 & \\
\hline
\end{tabular}

All metrics were derived from the outer border. Pearson's correlation coefficient was calculated after $\log _{10}$ transformation of all variables. Significance level alpha was set at 0.0167 .

constriction rate correlated very strongly with baseline area $(\mathrm{r}=0.8502, P<0.0001)$, whereas vertical diameter rate constriction demonstrated a strong correlation with vertical diameter at baseline $(\mathrm{r}=$ $0.5969, P<0.0001)$. Correlation was weakest for horizontal diameter $(\mathrm{r}=0.3554, P=0.0012)$. This finding of a significant association between larger baseline measurements and faster progression rates was also reported by Sujirakul et $\mathrm{al}^{24}$ when the cohort was divided into subjects with greater or lesser than a baseline vertical diameter of $3,000 \mu \mathrm{m}$. Interestingly, the association between horizontal diameter constriction and baseline metrics in their study was not significant, in keeping with our finding of ring horizontal diameter having the weakest correlation of the three metrics.

Table 5. Results of a Two-Way ANOVA

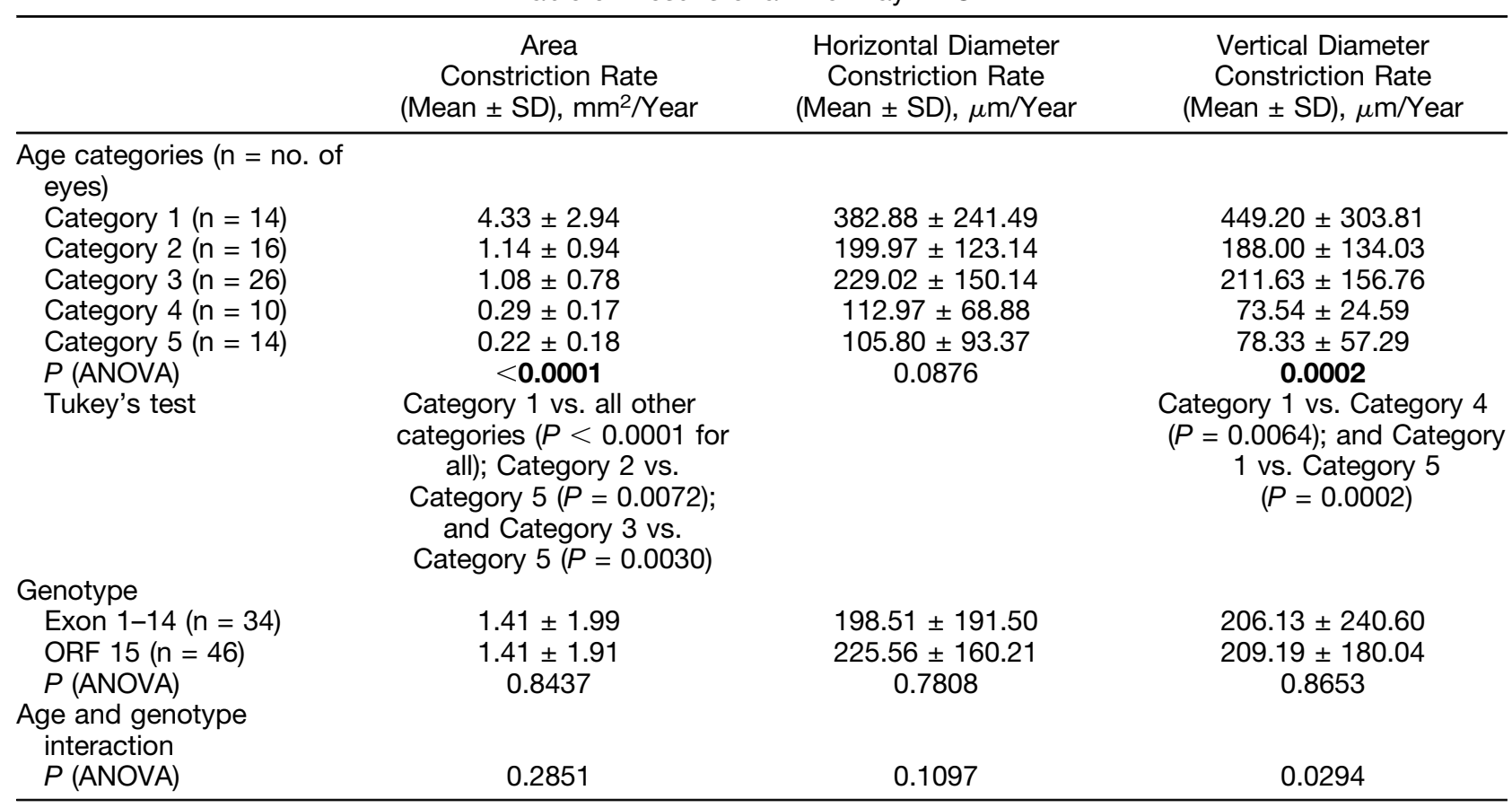

Ring metrics were derived from the outer border.

Significance level alpha for ANOVA was set at 0.0167 with analysis performed after $\log _{10}$ transformation of dependent variables. Post hoc multiple pairwise comparisons were performed using Tukey's test with $95 \%$ confidence levels. 


\section{Effects of Age and Genotype on Progression}

The effects of age were significant on both ring area and vertical diameter constriction rates. Post hoc comparisons showed significant differences between younger subjects, in particular those in age Category 1 compared with older age categories, indicating that progression is maximal in the youngest subjects. There was no effect of genotype on constriction rates.

Although speculative in nature, the effects of age could perhaps be explained by a biochemical model hypothesized by Clarke et $\mathrm{a}^{37}$ whereby each photoreceptor has a risk of death that is constant over time and occurring at random. In the case of younger subjects with larger rings, these large rings represent greater numbers of surviving photoreceptors. It is conceivable that more photoreceptors will die off at the early stages because of the greater numbers of photoreceptors present. This would give rise to a greater initial rate of decline. With age, as the numbers of surviving photoreceptors decrease, so will there be a concomitant decrease in the numbers of photoreceptors dying. Thus, the rate of decline slows in later age. This model can account for the exponential graph shown in Figure 4.

\section{Interocular Symmetry}

A high level of interocular symmetry at baseline and for overall rates of progression has been demonstrated in our study. Interocular symmetry at baseline has also been reported by others, for example by Robson et al ${ }^{11}$ who described a strong interocular correlation $(\mathrm{r}=$ 0.94 ) between internal radii of the FAF rings, as well as symmetry in electrophysiological testing $(r=0.94)$. More recently, Sujirakul et $\mathrm{al}^{30}$ also reported good overall interocular symmetry of vertical and horizontal diameter ring measures $(r=0.99$ and 0.98 , respectively). In addition, they did not find a difference in progression rates between eyes. ${ }^{24}$

\section{Measurement Variability}

Wakabayashi et al assessed interobserver variability for horizontal and vertical ring diameter metrics (not stated whether these were inner or outer ring measurements) and their coefficient of repeatability was 240 $\mu \mathrm{m}$ for horizontal and $250 \mu \mathrm{m}$ for vertical diameter. The $95 \%$ LOA was $-230 \mu \mathrm{m}$ to $270 \mu \mathrm{m}$ and -230 $\mu \mathrm{m}$ to $280 \mu \mathrm{m}$. Test-retest variability was $14.0 \%$ for horizontal diameter and $20.3 \%$ for vertical diameter. ${ }^{16}$ Three observers in Sujirakul et al measured both horizontal and vertical outer ring diameters. Limits of agreement pairs were calculated for each metric by comparing two observers at a time. The greatest value from the LOA pairs was used as a cutoff for mea- surement error, that is, measurements exceeding this cutoff were deemed clinically significant. Here, $421 \mu \mathrm{m}$ and $412 \mu \mathrm{m}$ were the cutoffs for vertical and horizontal diameter measurements, respectively. ${ }^{30}$

Sujirakul et $\mathrm{al}^{24}$ also assessed intraobserver variability-arguably more important for planned Phase I/II RP clinical trials. Test-retest variability was $9.5 \%$ for horizontal and $9.6 \%$ for vertical outer ring diameter metric. Annual rate of constriction in their study was 4.1\% (147 $\mu \mathrm{m} /$ year) and 4.0\% (121 $\mu \mathrm{m} /$ year) for horizontal and vertical diameter ring metrics, respectively. The 95\% LOA calculated from published data was $-137 \mu \mathrm{m}$ to $336 \mu \mathrm{m}$ for horizontal diameter and $-142 \mu \mathrm{m}$ to $316 \mu \mathrm{m}$ for vertical diameter metrics. Our intraobserver variability is comparable, with our testretest variability of $9.2 \%$ for horizontal diameter and $11.0 \%$ for vertical diameter metrics, and 95\% LOA of $-249 \mu \mathrm{m}$ to $347 \mu \mathrm{m}$ and $-230 \mu \mathrm{m}$ to $326 \mu \mathrm{m}$, respectively.

These studies solely used ring diameter metrics for which test-retest variabilities were twice the constriction rate. ${ }^{16,24,30}$ We have identified ring area (derived from outer border) to be a robust metric-as despite a marginally higher test-retest variability when compared with the diameter metrics, annual rate of constriction is greatest when quantified with the area metric, and approximately of the same magnitude as its corresponding test-retest variability (Table 1 ). We are confident that constriction rates obtained in our study are robust and real, as multiple observations with relatively long follow-up were obtained on our subjects, in addition to the robust method used to derive constriction rates.

\section{Assessing Suitability by Comparing Annual Mean Constriction Rates With Largest 95\% Limits of Agreement Value}

Mean rate of area constriction for our entire cohort was $1.42 \mathrm{~mm}^{2} /$ year, which is greater than the larger $95 \%$ LOA value of $1.11 \mathrm{~mm}^{2}$. In direct contrast, the mean rate of outer border horizontal diameter constriction was $214.1 \mu \mathrm{m} /$ year that is smaller than the larger LOA value of $347 \mu \mathrm{m}$. Likewise, vertical diameter constriction was $207.9 \mu \mathrm{m} /$ year, which again is smaller than the larger LOA value of $326 \mu \mathrm{m}$. As shown in Table 5 and Figure 5, constriction rates are greatest in younger subjects with those in age Category 1 having a mean area constriction rate of $4.33 \mathrm{~mm}^{2} /$ year. Thus, our findings of ring area as being the metric of choice to quantify progression may arguably be even more sensitive and robust in younger patients with inherently faster rates of progression, who moreover will likely constitute the target group for intervention. 


\section{Choice of Ring Metrics}

Previous groups have used various FAF metrics for analysis with no apparent consensus. These include measurements of ring area, ${ }^{15,23}$ ring horizontal diameter, ${ }^{15,16,18,24}$ ring vertical diameter, ${ }^{16,18,24,29}$ and ring radius. ${ }^{11,12,17,19,22}$ Others have preferred either measurements taken from the inner borders of the rings ${ }^{15}$ or from the outer borders, ${ }^{18,24,30}$ with the rationale that one border can be more accurately demarcated over the other. It is of note that none of these studies have provided results from objective investigations of measurement repeatability to substantiate their preferences. We have undertaken such assessments for ring and diameter metrics derived from both borders in our study. Furthermore, none of the studies that measure diameters on sequential images have corrected for image rotation, which represents a significant limitation.

\section{Conclusion}

Our study with a relatively long period of follow-up has allowed us to obtain sufficient data points to be the first FAF study to demonstrate an overall exponential decline in progression rate with age. Future studies will likely require longer periods of follow-up that is, 20 years or more to plot individual exponential decline.

Fundus autofluorescence imaging is reproducible and widely available in retinal clinics worldwide; hence, we advocate its regular use in monitoring progression in RP. Our finding of outer border-derived ring area as the most sensitive and valid metric to detect change will guide metric choice for interventional trials when assessing disease progression.

In addition, we have presented longitudinal data using FAF ring metrics to characterize baseline values and progression rates in $R P G R$-associated RP. The rate of progression is dependent on age and baseline ring size. In general, there is good overall interocular symmetry. These findings will be useful in informing patient selection and outcome measures in future treatment trials, as well as clinicians providing prognostic information to patients with $R P G R$-associated RP.

Key words: fundus autofluorescence, retinal diseases, retinitis pigmentosa, RPGR.

\section{References}

1. Hartong DT, Berson EL, Dryja TP. Retinitis pigmentosa. Lancet 2006;368:1795-1809.

2. Hamel C. Retinitis pigmentosa. Orphanet J Rare Dis 2006; $1: 40$.

3. Xu Y, Guan L, Shen T, et al. Mutations of 60 known causative genes in 157 families with retinitis pigmentosa based on exome sequencing. Hum Genet 2014;133:1255-1271.
4. You QS, Xu L, Wang YX, et al. Prevalence of retinitis pigmentosa in North China: the Beijing eye public health care project. Acta Ophthalmol 2013;91:e499-e500.

5. Haim M. Epidemiology of retinitis pigmentosa in Denmark. Acta Ophthalmol Scand Suppl 2002;233:1-34.

6. Pelletier V, Jambou M, Delphin N, et al. Comprehensive survey of mutations in RP2 and RPGR in patients affected with distinct retinal dystrophies: genotype-phenotype correlations and impact on genetic counseling. Hum Mutat 2007;28:81-91.

7. Shu X, Black GC, Rice JM, et al. RPGR mutation analysis and disease: an update. Hum Mutat 2007;28:322-328.

8. Sharon D, Sandberg MA, Rabe VW, et al. RP2 and RPGR mutations and clinical correlations in patients with $\mathrm{X}$-linked retinitis pigmentosa. Am J Hum Genet 2003;73:1131-1146.

9. Tee JJ, Smith AJ, Hardcastle AJ, Michaelides M. RPGR-associated retinopathy: clinical features, molecular genetics, animal models and therapeutic options. Br J Ophthalmol 2016;100: 1022-1027.

10. von Ruckmann A, Fitzke FW, Bird AC. Distribution of pigment epithelium autofluorescence in retinal disease state recorded in vivo and its change over time. Graefes Arch Clin Exp Ophthalmol 1999;237:1-9.

11. Robson AG, El-Amir A, Bailey C, et al. Pattern ERG correlates of abnormal fundus autofluorescence in patients with retinitis pigmentosa and normal visual acuity. Invest Ophthalmol Vis Sci 2003;44:3544-3550.

12. Popovic P, Jarc-Vidmar M, Hawlina M. Abnormal fundus autofluorescence in relation to retinal function in patients with retinitis pigmentosa. Graefes Arch Clin Exp Ophthalmol 2005; 243:1018-1027.

13. Robson AG, Saihan Z, Jenkins SA, et al. Functional characterisation and serial imaging of abnormal fundus autofluorescence in patients with retinitis pigmentosa and normal visual acuity. Br J Ophthalmol 2006;90:472-479.

14. Robson AG, Michaelides M, Saihan Z, et al. Functional characteristics of patients with retinal dystrophy that manifest abnormal parafoveal annuli of high density fundus autofluorescence; a review and update. Doc Ophthalmol 2008;116:79-89.

15. Aizawa S, Mitamura Y, Hagiwara A, et al. Changes of fundus autofluorescence, photoreceptor inner and outer segment junction line, and visual function in patients with retinitis pigmentosa. Clin Exp Ophthalmol 2010;38:597-604.

16. Wakabayashi T, Sawa M, Gomi F, Tsujikawa M. Correlation of fundus autofluorescence with photoreceptor morphology and functional changes in eyes with retinitis pigmentosa. Acta Ophthalmol 2010;88:e177-e183.

17. Robson AG, Tufail A, Fitzke F, et al. Serial imaging and structure-function correlates of high-density rings of fundus autofluorescence in retinitis pigmentosa. Retina 2011;31: 1670-1679.

18. Lima LH, Burke T, Greenstein VC, et al. Progressive constriction of the hyperautofluorescent ring in retinitis pigmentosa. Am J Ophthalmol 2012;153:718-727. 727.e711-e712.

19. Fakin A, Jarc-Vidmar M, Glavac D, et al. Fundus autofluorescence and optical coherence tomography in relation to visual function in Usher syndrome type 1 and 2. Vis Res 2012;75:60-70.

20. Robson AG, Lenassi E, Saihan Z, et al. Comparison of fundus autofluorescence with photopic and scotopic fine matrix mapping in patients with retinitis pigmentosa: 4- to 8-year followup. Invest Ophthalmol Vis Sci 2012;53:6187-6195.

21. Lenassi E, Troeger E, Wilke R, Hawlina M. Correlation between macular morphology and sensitivity in patients with retinitis pigmentosa and hyperautofluorescent ring. Invest Ophthalmol Vis Sci 2012;53:47-52. 
22. Greenstein VC, Duncker T, Holopigian K, et al. Structural and functional changes associated with normal and abnormal fundus autofluorescence in patients with retinitis pigmentosa. Retina 2012;32:349-357.

23. Iriyama A, Yanagi Y. Fundus autofluorescence and retinal structure as determined by spectral domain optical coherence tomography, and retinal function in retinitis pigmentosa. Graefes Arch Clin Exp Ophthalmol 2012;250:333-339.

24. Sujirakul T, Lin MK, Duong J, et al. Multimodal imaging of central retinal disease progression in a 2-year mean follow-up of retinitis pigmentosa. Am J Ophthalmol 2015;160:786-798 e784.

25. Delori FC, Dorey CK, Staurenghi G, et al. In vivo fluorescence of the ocular fundus exhibits retinal pigment epithelium lipofuscin characteristics. Invest Ophthalmol Vis Sci 1995;36:718-729.

26. Feeney-Burns L, Berman ER, Rothman H. Lipofuscin of human retinal pigment epithelium. Am J Ophthalmol 1980; 90:783-791.

27. Dorey CK, Wu G, Ebenstein D, et al. Cell loss in the ageing retina: relationship to lipofuscin accumulation and macular degeneration. Invest Ophthalmol Vis Sci 1989;30:1691.

28. von Ruckmann A, Fitzke FW, Bird AC. Distribution of fundus autofluorescence with a scanning laser ophthalmoscope. Br J Ophthalmol 1995;79:407-412.

29. Murakami T, Akimoto M, Ooto S, et al. Association between abnormal autofluorescence and photoreceptor disorganization in retinitis pigmentosa. Am J Ophthalmol 2008;145:687-694.
30. Sujirakul T, Davis R, Erol D, et al. Bilateral concordance of the fundus hyperautofluorescent ring in typical retinitis pigmentosa patients. Ophthalmic Genet 2015;36:113-122.

31. Massof RW, Dagnelie G, Benzschawel T. First order dynamics of visual field loss in retinitis pigmentosa. Clin Vis Sci 1990;5: $1-26$.

32. Iannaccone A, Kritchevsky SB, Ciccarelli ML, et al. Kinetics of visual field loss in Usher syndrome type II. Invest Ophthalmol Vis Sci 2004;45:784-792.

33. Berson EL. Long-term visual prognoses in patients with retinitis pigmentosa: the Ludwig von Sallmann lecture. Exp Eye Res 2007;85:7-14.

34. Birch DG, Anderson JL, Fish GE. Yearly rates of rod and cone functional loss in retinitis pigmentosa and cone-rod dystrophy. Ophthalmology 1999;106:258-268.

35. Sandberg MA, Rosner B, Weigel-DiFranco C, et al. Disease course of patients with $\mathrm{X}$-linked retinitis pigmentosa due to RPGR gene mutations. Invest Ophthalmol Vis Sci 2007;48: 1298-1304.

36. Cai CX, Locke KG, Ramachandran R, et al. A comparison of progressive loss of the ellipsoid zone (EZ) band in autosomal dominant and $\mathrm{x}$-linked retinitis pigmentosa. Invest Ophthalmol Vis Sci 2014;55:7417-7422.

37. Clarke G, Collins RA, Leavitt BR, et al. A one-hit model of cell death in inherited neuronal degenerations. Nature 2000; 406:195-199. 